\title{
GLOBALIZAÇÃO: PARA QUEM?
}

\author{
Natan Ben-Hur Braga' \\ Carlos Roberto da Silva ${ }^{2}$
}

Resumo: Em meio a toda essa complexidade mundial, quando os governos já aparecem com contornos supranacionais, quando as corporações da mesma forma suplantam os espaços físicos territoriais, surgem questionamentos que impulsionam à pesquisa, uma vez que a composição de todo esse amálgama social é composta por pessoas, sujeitos invisíveis cujas repercussões de tomadas de decisão lhe afetam diretamente. Por tal motivo, o que se pretende explorar nesse estudo é a necessidade de que esse mesmo sujeito possua meios de participar de tais decisões sem que seja pelo simples elemento do sufrágio. Que sua participação seja efetiva, digna e cujas consequências sejam direcionadas e redirecionadas de acordo com as suas verdadeiras necessidades em um pulsar dinâmico e eficaz.

Palavras-chave: Sujeito. Constitucionalismo intercultural. Democracia participativa.

\section{INTRODUÇÃO}

É recorrente o debate no campo jurídico científico acerca da necessidade do reconhecimento político de determinados

1 Doutorando em Ciência Jurídica pela UNIVALI, Professor da UNIVALI nas cadeiras de Direito Civil: Obrigações e Direito Civil: Contratos. E-mail: natanadv@terra.com.br

2 Graduado em Direito pela Universidade do Vale do Itajaí - UNIVALI, Pós-graduado em Direito Civil, Mestre em Ciência Jurídica e Doutorando em Ciência Jurídica, em dupla titulação, pela Universidade do Vale do Itajaí e Universidade de Alicante, na Espanha. Professor do curso de Direito da Universidade do Vale do Itajaí - UNIVALI. Magistrado lotado na Vara da Fazenda Pública da Comarca de Itajaí. E-mail: crs4766@tjsc.jus.br 
impulsos, a fim de tornar reais e existentes determinadas políticas sociais que possibilitem um desenvolvimento humano adequado às necessidades da atualidade, viabilizando ao maior número de pessoas possível, os contatos com instrumentos que possibilitem seu desenvolvimento pessoal no campo intelectual e material, permitindo, assim, a formação de uma teia social desenvolvida e habitada por sujeitos que possam autodesenvolverem-se, bem como proporcionar e indicar caminhos aos seus descendentes ou ainda, às gerações futuras em que possa influenciar de alguma maneira.

$\mathrm{Cruz}^{3}$, com inteira razão, exorta que:

A percepção da existência de direitos vinculados à pessoa de modo indissociável experimentou uma notável evolução. O desenvolvimento do princípio democrático e o acesso de camadas cada vez mais amplas da população à vida política, permitiram tornar evidente que o efetivo exercício dos direitos de Liberdade e de cidadania política só ganham sentido se algumas condições materiais forem garantidas. Sem dispor dos meios básicos para garantir uma qualidade mínima de vida, poucas serão as "esferas próprias" que possam estar imunes a ingerências exteriores.

No entanto, ao que parece, existe uma série de atores sociais que poderiam possibilitar definitivamente esse objetivo social, desde os nacionais, tais como governos e empresas, até os supranacionais também governos e empresas, consideradas as instituições que hoje já não se conformam em espaços físicos e que, ao contrário, se constituem em instituições políticas sui generis de grande escala. ${ }^{4}$

Discorrer sobre essa premissa é o objetivo deste trabalho, apontado direcionamentos a partir da observação do fenômeno estudado pela sociologia e pelo Direito, aqui, em um exercício

3 CRUZ, Paulo Márcio. Fundamentos do Direito Constitucional. 1 ed. Curitiba: Juruá, 2002, p. 161.

4 BECK, Ulrich. Liberdade ou capitalismo. Trad. De Luiz Antônio Oliveira de Araújo. São Paulo: Littera Mundi, 2011, p. 111. 
do conceito Kantiano do pensar livremente no uso público da razão, e ver as fraquezas e as injustiças da ordem existente é explicitar um apelo ao governante para que sejam feitas reformas. ${ }^{5}$

\section{O PARADÓXO: A QUEM PERTENCE O DIREITO?}

Um fenômeno bem interessante destaca-se a partir da observação de Boaventura de Souza Santos ${ }^{6}$ quando revela: Pienso que nunca antes tuvimos una distancia tan grande entre teoría política y práctica política.

Sem pretender investigar os motivos dessa distância, é possível observar e constatar na realidade a existência de uma problemática que assola toda a sociedade, que ao mesmo tempo em que pretende chegar ao mais extremo caminho da tecnologia, relega tratamento aos seres vivos e ao planeta, que pode ser contextualizado como um grande paradoxo acerca da própria sanidade do sistema e dos seus gestores.

De outro viso, igualmente é certo ponderar que a teoria política hoje posta em prática, acabou sendo 'importada' pelos Estados democráticos que foram se formando, a partir de modelos estabelecidos em outras épocas e sociedades, parecendo não mais servir, sobretudo aos emergentes países da América Latina, África e Ásia. Esse pensamento é perfilado por Santos?

La teoría política fue desarrollada en el Norte global, básicamente en cinco países: Francia, Inglaterra, Alemania, Italia y Estados Unidos. Fueron estos países que, desde mediados del siglo XIX, inventaron todo un marco teórico que se consideró universal y que se aplicó a todas as sociedades. Hoy por hoy, nos damos cuenta que estos conceptos

5 ZIZEK, Slavoj. O ano em que vivemos perigosamente. Trad. de Rogério Bettoni. 1. Ed. São Paulo: Boitempo, 2012, p. 11.

6 SANTOS, Boaventura de Souza. La Reinvención del estado y el Estado Plurinacional.Santa Cruz de la Sierra, Bolivia: CENDA, 2007. p. 64.

7 SANTOS, Boaventura de Souza. La Reinvención del estado y el Estado Plurinacional, p. 12. 
ya no se adaptan muy fácilmente a nuestras sociedades.

No entanto, o falado paradoxo que despreza o ser (o Sujeito de Direito) em seu hábitat, em detrimento do apogeu tecnológico-científico, está por atingir as estruturas dos sistemas e formas de governo, contribuindo para o enfraquecimento do Poder e controle social antes de certa forma exercido pelo welfare state, tudo a aparentemente a confirmar a necessidade de se instrumentalizar políticas sociais internas e transnacionais.

A esse panorama, destaca-se que as transformações vividas pelas sociedades globalizadas são sentidas em todos os níveis de convivência, experiências, que se vê, ocorrem em nível mundial e afetam direta e frontalmente a relação entre os indivíduos, grupos, empresas e governos. Lipovetsky ${ }^{8}$, discorrendo sobre essa realidade, enfatiza:

La época en que vivimos está caracterizada por una poderosa e irresistible tendencia a la unificación del mundo. En Francia se denomina mundialización y en otras partes globalización. Esta formidable dinámica coincide con la conjunción de fenómenos económicos) liberalización de mercados en un capitalismo planetario), innovaciones tecnológicas (nuevas tecnologías de la información y la comunicación) y cambios radicales de la situación geopolítica (hundimiento del imperio soviético). Aunque esta unificación del mundo no es un fenómeno en absoluto reciente (estamos en una <segunda globalización>) ni una realidad completa, no es menos cierto que representa un cambio general y profundo tanto en la organización como en la percepción de nuestro mundo.

E continua:

Durante la modernidad, Occidente se impuso como centro único de la tecnociencia, procla-

8 LIPOVETSKY, Gilles; JUVIN, Hervé. EI Occidente Globalizado: Un debate sobre la cultura planetaria. Barcelona: Anagrama, 2011, p. 13. 
mando su idoneidad para aportar al mundo sus luces y sus éxitos. Este capítulo de la historia se ha cerrado. En la era hipermoderna algunos países emergentes empiezan, aunque sea tímidamente, a competir con Occidente en el desarrollo de sectores punta como la informática, las biotecnologías, la industria farmacéutica. En el sector químico y el de las nanotecnologías, las publicaciones chinas son ya más numerosas que las de Estados Unidos. La posición de estas nuevas economías avanza también en los sectores de la electrónica, de la industria espacial y aeronáutica. Por el momento, lógicamente, los dominios que permiten la aparición de auténticas innovaciones siguen siendo todavía limitados: en materia de alta tecnología, Occidente dista mucho de ser destronado. Pero no es menos cierto que la cultural-mundo que despunta verá el fin del monopolio occidental de lo tecnocientífico. ${ }^{9}$

Assim, e voltando a pensar em como o sistema jurídico pode contribuir - pois essa é a sua principal função - para equacionar esse complexo problema social, há que se alcançarem avaliações que levem a uma prática concreta, que primem por observar, como ilustrado por Alexy ${ }^{10}$, uma dimensão empírica que deve avançar para analisar a construção do direito por meio das normas jurídicas positivadas no ordenamento e da aplicação do direito, verificando-se, inclusive, o discurso jurídico por trás dos atos dos diversos protagonistas do direito.

Cuida-se de uma análise mais ampla do que da simples construção de validade das normas contidas no ordenamento jurídico, representando uma dimensão dirigida ao estudo do direito enquanto engrenagem em funcionamento, aplicada para a consecução de determinados objetivos, evoluindo-se, assim, de um patamar de mera constatação do conteúdo pré-existente da

9 LIPOVETSKY, Gilles; JUVIN, Hervé. EI Occidente Globalizado: Un debate sobre la cultura planetaria, p. 46.

10 ALEXY, Robert. Teoria dos direitos fundamentais. Tradução Virgílio Afonso da Silva. 2 Ed. Malheiros: São Paulo. 2008. p. 669. 
norma, para uma plataforma que crie condições de produção de um Direito mais bem adequado aos anseios da Sociedade. ${ }^{11}$

Mas não só isso, também uma dimensão normativa que possua natureza crítica. Esta transcende a dimensão empírica para ganhar um condão propositivo que visa melhor compreender a prática jurídica, tecendo uma análise crítica e apontando as possíveis soluções e a construção de um método capaz de fornecer respostas corretas aos casos concretos.

Tais dimensões devem estar agregadas na mens legislatoris, a fim de que se possa ver aliadas as vontades políticas e as aspirações sociais.

Desse modo, como observa Canotilho ${ }^{12}$, a positivação dos direitos sociais como direitos subjetivos públicos, isto é, direitos inerentes ao espaço existência dos cidadãos, deve alcançar o máximo de concretização possível, uma vez que:

O problema atual dos direitos sociais ou direitos a prestações em sentido estrito está em levarmos a sério o reconhecimento constitucional de direitos como o direito ao trabalho, o direito à saúde, o direito à educação, o direito à cultura, o direito ao ambiente $[. .$.$] considerarem certas posições jurí-$ dicas de tal modo fundamentais que a sua ou não garantia não pode ser deixada aos critérios (ou ao arbítrio) de simples maiorias parlamentares. ${ }^{13}$

Estas objeções devem ser tomadas a sério, enquanto globalmente consideradas, mas baseiam-se todas numa conjectura que aqui devemos refutar ou confirmar - a de que as posições jurídico-prestacionais se reduzem a um único tipo de situação jurídica, regulada por normas indeterminadas, vagas, injustificáveis, não acionáveis, e, em último termo, não

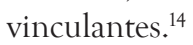

11 ALEXY, Robert. Teoria dos direitos fundamentais, p. 81-82.

12 CANOTILHO. Estudos Sobre Direitos Fundamentais. $2^{\mathrm{a}} \mathrm{ed}$, Coimbra: Coimbra Editora, 2008, p. 38.

13 CANOTILHO. Estudos Sobre Direitos Fundamentais, p. 51.

14 CANOTILHO. Estudos Sobre Direitos Fundamentais, p. 54. 
Os direitos fundamentais e sociais derivados da Constituição Federal aparentam uma estabilidade de garantias que ao serem lidas parecem suficientes em si, mas que, no entanto, concretamente revelam um verdadeiro abismo entre o discurso e a prática.

Observa, ainda, o autor acima citado, que a implementação desses direitos compete ao executivo, por meio de políticas públicas:

(...) por meio da Constituição fica bastante claro que os mesmos devem ser implementados por meio de uma série de políticas públicas visando à saúde, educação e outros direitos sociais consagrados no catálogo constitucional, contudo, a forma como estas políticas sociais devem ser executadas deveriam ser um juízo discricionário que caberia ao poder executivo, restando ao judiciário a fiscalização da existência, legalidade, constitucionalidade e eficiência dos meios adotados para a devida implementação de tais ações prestacionais do Estado numa clara distinção entre direitos sociais e políticas públicas de implementação de tais direitos sendo possível falar-se de uma discricionariedade legislativa pautada por limites jurídico-materiais normativamente plasmados na norma da constituição. ${ }^{15}$

Tal fato, constatado como realidade atual, não apenas nacional como também em muitas das Democracias ocidentais, é metaforizado por Freud apud Morin ${ }^{16}$ como o desenvolvimento do fermento de sua própria destruição.

Não há mais tempo para ponderações acerca da responsabilidade de atuar como vanguardista da ação, não é possível manter tal estado de coisas que fazem do mundo do ordenamento jurídico algo que regule apenas satisfatoriamente as relações entre pessoas e entre pessoas e governos.

15 CANOTILHO. Estudos Sobre Direitos Fundamentais, p. 33.

16 MORIN, Edgar. La vía: para el futuro de la humanidade. Trad. De Núria Petit Fontseré. Barcelona: Paidós, 2011. p. 53. 
Não se pode olvidar que o mundo do direito como objeto que é da ciência jurídica é um mundo artificial que deve ser produzido e conduzido a viabilizar e possibilitar a vida cidadã, um mundo no qual a política tem a responsabilidade de dizer a realidade: "Cómo es y cómo será el Derecho depende de la política y de su capacidad de realizar los principios del texto constitucional." ${ }^{17}$

\section{O CONSTITUCIONALISMO PARA UMA DEMOCRACIA PARTICIPATIVA}

Crises de vários talantes, no dizer Boaventura de Souza $\operatorname{Santos}^{18}$, representaram a necessidade de mudança de paradigmas institucionalizados e historicamente o constitucionalismo antigo apenas ratificava a maneira como os povos estavam constituídos, evoluindo para o constitucionalismo moderno como a seguir se verá na observação de Matteucci ${ }^{19}$ - no qual os povos impunham regras mediante um contrato social, a fim de regular as relações derivadas de um poder constituído, repartido e submetido aos freios e contrapesos de separação de poderes e regulações, liberdade individual etc., uma vez que estavam lutando contra a cultura romana deísta e imperialista.

Lo original del constitucionalismo moderno consiste en su aspiración a una constitución escrita, que contenga una serie de normas jurídicas orgánicamente relacionadas entre ellas, en oposición a la tradición medieval, que se expresaba en "leyes fundamentales" consuetudinarias.

[...] En suma: el constitucionalismo moderno o, mejor, los albores del liberalismo están estrechamente unidos a la batallaya la victoria del principio

17 FERRAJOLI, Luigi; MANERO, Juan Ruiz. Dos Modelos de Constitucionalismo: una conversación. Madrid: Editorial Trotta, 2012.

18 FERRAJOLI, Luigi; MANERO, Juan Ruiz. Dos Modelos de Constitucionalismo: una conversación, p. 21-22.

19 MATTEUCCI, Nicola. Organización Del poder y libertad: historia del constitucionalismo moderno. Madrid: Trotta, 1998.p. 24 e 56. 
de la tolerancia religiosa, entendida no como mera concesión desde arriba sino como un verdadero y auténtico derecho del individuo a la libertad religiosa, en el cual reside el verdadero germen de la moderna libertad política.

[...] culminado el processo de secularización, no fundamenta la legitimidad del poder en el derecho divino del rey, ni em la tradición, sino en el consenso racional de los ciudadanos. El segundo carácter se refiere a la función: se quiere una constitución escrita no sólo para impedir un gobierno arbitrário e instaurar un gobierno limitado, sino para garantizar los derechos de los ciudadanos y para impedir que el Estado los viole.

[...] Para esta finalidad, para garantizar realmente los derechos, la constitución debe ser rígida e inflexible, en el sentido de que sus normas no pueden ser modificadas ni interpretadas por el poder legislativo ordinario, ya que son superiores jerárquicamente. ${ }^{20}$

Dessa forma, o constitucionalismo moderno criou uma ideia totalmente oposta que teria de contradizer com os usos e costumes daquela fase histórica, mas que, no entanto, tendia a ser monocultural.

A problemática que se instituí, no entanto, é justamente aquela que revela a ideia de que a monocultura hegemônica é a que se revela mais apropriada e cômoda.

Em se tratando de um país como o Brasil, a manutenção das várias culturas regionais, mesmo que submetidas a um eixo cultural que tende a ser um terceiro tipo, revela a necessidade de se intensificar o trabalho de reconhecimento dessas vertentes, a fim de poder fazer com que estas se revelem mais fortes e independentes ao mesmo tempo em que se tornem passíveis de adicionar e compreender culturas outras, além das nacionais, também as transnacionais.

20 MATTEUCCI, Nicola. Organización Del poder y libertad: historia del constitucionalismo moderno, p. 25. 
A tendência do mundo é compartir além das mercadorias, todas as diversidades onde, sem sombra de dúvida, está incluída a diversidade cultural, a ponto Morin ${ }^{21}$ dizer que tais diversidades estão gestando para um futuro próximo um porvir mestiço da humanidade.

Hay un momento histórico en que estas constitucionalidades invisibles se tornan visibles y empiezan a verse como otro constitucionalismo antiguo que va competir y chocar con el constitucionalismo moderno. Es el constitucionalismo intercultural, plurinacional y pluricultural que hoy estamos viendo que está intentando en varios países. [...] Son formas de articular la contradicción que emergió dentro del Estado moderno mono cultural. Esta constitucionalidad informal es antiquísima, estaba en la sociedad y ahora es visible por la acción de actores políticos que, además, lo ponen en la agenda política. ${ }^{22}$

Em pensar não catastrófico, porém realista e ponderado, é de se sopesar, nesse quadro de ideia reformadora do constitucionalismo vigente, os malefícios causados pelo processo de Globalização. Assim, sem desconhecer os benefícios à vida social do ser humano, destacam Hessel e Morin ${ }^{23}$ inevitáveis contraindicações, e a necessidade de se enaltecer os aspectos globalizantes que magnetizem a solidariedade entre os povos, assim como a manutenção de suas diversidades culturais:

Hay que saber globalizar y desglobalizar a la vez. Es preciso seguir con la globalización, que nos proporciona una comunidad de destino como seres humanos de cualquier origen, amenazados por peligros mortales. [...] Proponemos perpetuar y desarrollar todo lo que la globalización aporta en concepto de intersolidaridades y de fecundi-

21 MORIN, Edgar. La vía para el futuro de la humanidad, p. 53.

22 MORIN, Edgar. La vía para el futuro de la humanidad, p. 23.

23 HESSEL, Stéfhane; MORIN, Edgar. EI camino de la esperanza: una llama a la movilización cívica. Traducción de Rosa Alapont. Barcelona: Ediciones Destino, 2012, p. 18. 
dades culturales, pero, al mismo tiempo, proponemos devolver las autonomías vitales a lo local, a lo regional, a lo nacional, así como salvaguardar y favorecer por todas partes las diversidades culturales. Tenemos que desglobalizar para ceder todo el espacio a la economía social y solidaria, para proteger la economía de la región, preservar la agricultura de subsistencia y la alimentación ligada a ella, la artesanía y los comercios de proximidad, con el fin de atajar la desertificación de los campos y la disminución de los servicios en las áreas periurbanas en dificultad.

E continuam:

Asimismo, debemos indicar que la fórmula estandarizada del desarrollo ignora las solidaridades, el saber y la destreza de las sociedades tradicionales, y que es preciso repensar y diversificar el desarrollo de tal manera que preserve las solidaridades propias de los envolvimientos comunitarios.

Por isso, esse constitucionalismo que surge como uma dialética entre o constitucionalismo antigo e o constitucionalismo moderno, como uma terceira via, denominado de Intercultural, pelo menos por enquanto, parece representar o que há de tendência positiva às predições do mundo atual.

Veja-se que a todo tempo, destacados agora como acontecimentos mais recentes, os povos, principalmente os ocidentais, dão conta de que suas reivindicações são muito semelhantes, seja na primavera Árabe, seja na invasão a Wall Street, seja nas recentes manifestações - aqui, dando-se guarida apenas às pacíficas - pelo Brasil afora, dentre outros: Ucrânia, ao que parece exitosa com a deposição do governo pró Rússia; e Venezuela, cujos entraves parecem estar longe de um fim pacífico e efetivamente democrático.

Buscar nesse imaginário social a base do constitucionalismo atual, necessário às aspirações sociais como um todo, com possibilidade de incluso através da detecção das necessidades, 
que até podem ser objeto de pautas programáticas, mas que, no entanto, programáticas com prazos, com ações verdadeiras e materializáveis em um curto espaço de tempo.

Ao que se vê essa proposta de um constitucionalismo atual intercultural proposta por Morín na bibliografia aqui citada, leva em consideração a necessidade de sua flexibilização, de incursão nas mais diversas culturas a fim de que os países possam, resguardadas suas culturas próprias, como já se falou, convergir para um desenvolvimento conjunto e sustentável, no qual a parceria é a tônica, jamais podendo-se falar em dominação ou submissão/exploração.

Não se pode desconsiderar o fato de que sempre haverá ricos e pobres, mas a tônica está fundamentalmente na solidariedade entre os povos.

Fazem-se tais considerações também para chamar a atenção quanto à necessidade de as grandes corporações tomarem para si obrigações de tal monta que possibilitem por suas vias essa disseminação cultural.

Para tanto, necessário se faz que o Poder Constituinte se mantenha fortalecido para não permitir - e aqui a colaboração empresária e a lisura política são essenciais - que tais instituições privadas indiquem os caminhos da política.

Caso isso venha a acontecer, a força institucionalizada do Estado deve intervir, uma vez que se tal circunstancia tornar-se prática disseminada, é bem possível que as liberdades estejam seriamente ameaçadas.

$\mathrm{Cruz}^{24}$ reconhece essa necessidade, já verificada em tempos passados:

A intervenção do Estado na vida econômica e social passou a se configurar como um elemento necessário para impedir crises cíclicas e para garantir um mínimo de bem-estar a grande parte da população. O Estado passou a ser configurado, paulatinamente - principalmente após a Segunda

24 CRUZ, Paulo Márcio. Fundamentos do Direito Constitucional. 1 ed. Curitiba: Juruá, 2002, p. 161. 
Guerra Mundial - como intervencionista ou, numa fórmula mais ampliada, como um Estado Social e com função social, decidido a promover - ou a impedir - determinadas ações sociais, culturais e econômicas.

Acentua-se que a Liberdade individual e coletiva devem ser consideradas como um Bem Público, uma vez que é a partir desse marco que tudo mais se regula em uma Democracia.

Também sob esse ponto de vista, devem estar contidos nesse conceito novos direitos fundamentais que virão com a ideia de Constitucionalismo Intercultural, tais como a educação, el derecho al agua, a la tierra, a la soberanía alimentaria, a los naturales, a la biodiversidad, a los bosques y a los saberes tradicionales. ${ }^{25}$

Ao que parece, um constitucionalismo dessa espécie dependeria de uma democracia forte, na qual o papel da educação e da coalizão de culturas seria extremamente importante.

Outras propostas de um Constitucionalismo Intercultural são aqui colacionadas, a fim de possibilitar algumas das estruturas necessárias ao seu desenvolvimento:

O Estado e o Direito Transnacional poderiam ser propostos a partir de um ou mais espaços públicos transnacionais, ou seja, a criação de espaços públicos que possam perpassar estados nacionais. Logo, o Estado e o Direito Transnacional poderiam ter, enquanto proposta para a discussão, as seguintes características: a) [...] b) Formação por instituições com órgãos e organismos de governança, regulação, intervenção e aplicação das normas transnacionais; c) capacidade fiscal em diversos âmbitos transnacionais [...] d) atuação em âmbitos difusos transnacionais [...] f) implantação gradativa de instrumentos de democracia transnacional deliberativa e solidária; g) constituição dos espaços públicos transnacionais, especialmente com base na cooperação, solidariedade e no consenso [...] pode-se propor que o prefixo

25 SANTOS, Boaventura de Souza. La Reinvención del estado y el Estado Plurinacional. Santa Cruz de la Sierra, Bolivia: CENDA, 2007. p. 31-33. 
trans indique que a estrutura pública transnacional poderia perpassar vários estados [...] é a possibilidade de fundação de vários espaços públicos de governança, regulação e intervenção, cujos mecanismos de controle e funcionamento seriam submetidos às sociedades transnacionalizadas [...] É como Ulrich Beck manifesta-se, ao escrever que a transnacionalização é uma conexão forte entre espaços nacionais, inclusive de modo que não seja pensado internacionalmente, e sim no surgimento de algo novo, de um espaço transpassante, que já não se encaixa nas velhas categorias modernas. ${ }^{26}$

[...] juntando o prefixo trans e o conceito e caracterização de Nação Jurídica, entender por Transnacional os novos espaços públicos não vinculados a um território específico, que perpassam a ideia tradicional de Nação Jurídica, aceitam a pluralidade como premissa e possibilitam o exercício de poder a partir de uma pauta axiológica consensual, destinada a vializar a proposição de um novo pacto de civilização. ${ }^{27}$

Como se sabe, ensaios tais como este pretendem discutir os assuntos postos no intuito de apontar possibilidades.

A democracia atual, como forma de governo, qual seja, a representativa, ao que parece estaria com sérias dificuldades de se consolidar em um constitucionalismo que viesse a primar pela interculturalidade, uma vez que os freios constitucionais, principalmente quanto ao conceito de soberania, estariam a impossibilitar o desenvolvimento necessário ao fim almejado.

No entanto, ao que parece, a Democracia Participativa, por outro lado, teria muito a contribuir com o desenvolvimento dinâmico necessário à implementação da interculturalidade.

Passa-se então a tecer considerações acerca dessa modalidade, que parece possibilitar um desenvolvimento mais adequado à conformação do modelo.

26 CRUZ, Paulo Márcio; STELZER, Joana (Orgs.) Direito e Transnacionalidade. Curitiba: Editora Juruá, 2010, p. 56.

27 CRUZ, Paulo Márcio; STELZER, Joana (Orgs.) Direito e Transnacionalidade, p. 61. 


\section{DEMOCRACIA PARA UM NOVO CONSTITUCIONALISMO}

Considerando a evidência de que a Democracia Representativa já não é suficiente para a pós-modernidade, a Democracia Participativa por sua vez, como revela Wolkmer, ${ }^{28}$ deve atender a um equilíbrio de poderes entre os legitimados pelos votos, os legitimados por suas iniciativas de base e os legitimados por seus conhecimentos técnicos profissionais. Nenhum deles, sozinho, pode pretender ter a verdade da vontade democrática.

Nesse sentido a Democracia Participativa faz aflorar o Princípio da Participação Cidadã que será tratado mais a frente, cujo fundamento revela a possibilidade de tomada de decisões que devem decorrer do imaginário social, daquilo em que a Sociedade acredita ser mais viável para a sua sobrevivência como tal.

Nesse caminhar, pondera Diaz-Salazar ${ }^{29}$ :

El paradigma es la democracia participativa, y el instrumento de intervención de la sociedad civil en las políticas públicas del Estado es el presupuesto participativo.

Destarte, uma renovação na teoria democrática requer, no dizer de $\mathrm{Cruz}^{30}$, uma reformulação de critérios, principalmente naquele que exalta a participação como coluna, reformulação esta que evidencia um não confinamento no ato de votar. Para tanto, uma nova ideia que se apresenta mediante a necessidade de incursão na Democracia Representativa com a finalidade de torná-la Democracia Participativa.

Não há dúvidas de que para que isto ocorra, vários outros critérios componentes da infraestrutura social, tal como, e de modo especial, o político, devem sofrer polimentos generosos, a fim de tornar possível a renovação dos critérios democráticos

28 WOLKMER, Antonio Carlos. Ideologia, Estado e Direito.p. 95.

29 DÍAZ-SALAZAR, Rafael. Desigualdades internacionales: justicia ya. Barcelona: Icaria editorial, 2011, p.76.

30 CRUZ, Paulo Márcio. A Democracia Representativa e a Democracia Participativa. Universidade de Alicante. Espanha. 2007, p. 12. 
acima exemplificados, bem como para poder ver implementado o constitucionalismo intercultural.

Essa crítica é estabelecida, principalmente ao político, tendo em vista que, na atual dimensão, ele se transformou em uma representatividade extremamente setorial e especializada, quando busca interesses dos seus representados, que por sua vez são uma minoria e que contrariam as bases da própria Democracia Representativa, e especializada quando tornam esse ambiente uma carreira pernóstica derivada justamente do único interesse desses grupos minoritários.

Isso torna impossível que as maiorias estejam representadas do modo que lhes convenha, principalmente porque esse modo de conveniência é geralmente contrariado pelos interesses de minorias setorizadas (aqui o problema das empresas acima citado), as quais comandam o sistema político-econômico, afastando qualquer possibilidade de atingir aos anseios sociais maiores e gerais.

Isso torna o sistema da Democracia Representativa uma verdadeira rede cujos emaranhados de leis e decisões administrativas, como o seu próprio sustentáculo, e em razão dos vazios que formam essa mesma rede, uma inviabilidade.

Daí que a Democracia Participativa e para sua implementação como a possível saída para tais argumentos, como preceitua Santos ${ }^{31}$ requer uma nova teoria democrática, a qual deverá proceder a re-politização global da prática social, resultando em um vasto campo político a ser explorado, o qual certamente permitirá que se encontre novas formas de comando, ao mesmo tempo em que criará novas oportunidades para o exercício de novas formas de Democracia e de cidadania.

A Democracia Participativa como modelo representa um passo a mais na caminhada democrática. Sua formação indica que deixará de ser tratada como procedimento, como instrumento, como adjetivação e forma, para tornar-se um valor social a firmar os Bens Públicos como categorias generalizadas e substanciais.

31 SANTOS, Boaventura de Souza. Pela mão de Alice: o social e o político na pós-modernidade, p. 271. 
Imagine-se que, para que sua implementação fosse possivel, a ideia de cidadão ${ }^{32}$ representaria um sujeito de direito com formação axiológica suficiente para poder, como sujeito, mas conjuntamente com os seus pares defender os ideais sociais locais e transnacionais, trazendo à baila uma espiritualidade diversa daquela que formou a Democracia Representativa, ou seja, em uma determinada religião.

Como revela $\mathrm{Cruz}^{33}$ é importante salientar que o modelo de Democracia participativa não supõe tanto a participação direta no ato final de adoção de decisões políticas, mas sim a participação mais efetiva nos processos de decisão que levam posteriormente às decisões definitivas. Para isso a Educação elevada ao conceito de Bem Público, seria o veículo possibilitador e viabilizador das tomadas de decisões a partir do imaginário social bem formado e informado.

Ou ainda, reflete o autor supra referenciado que a participação política não se conduz tanto no momento da manifestação da vontade do poder, mas principalmente no processo de formação dessa vontade e a garantia de que tal vontade, na prática, será respeitada ${ }^{34}$, ou seja, materializada em práticas que concretizem a ideia, sem desculpas, sem engodos, sem desvios.

Morín ${ }^{35}$ sugere a Democracia Participativa, principalmente em escalas locais, em um novo tipo de governança instituído com a conjunção das instâncias participativas cidadãs, das instâncias políticas, e administrativas, locais e regionais, dos profissionais competentes em domínios a serem debatidos e suprimidos. ${ }^{36} \mathrm{E}$ ainda, que a Democracia Participativa deve buscar revitalizar o espírito da comunidade, solidariedade e responsabilidade, regenerar o civismo em sua base, lá onde fermentam tantas boas vontades subempregadas.

32 Aqui não se considera as críticas à categoria cidadão que pretendem enclausurá-la como pejorativa e sectarista, como representação de minorias.

33 CRUZ, Paulo Márcio. A Democracia Representativa e a Democracia Participativa, p. 14.

34 CRUZ, Paulo Márcio. A Democracia Representativa e a Democracia Participativa, p. 15.

35 MORIN, Edgar. A Via para o futuro da humanidade. Tradução de Edgard de Assis Carvalho e Mara Perassi Bosco. Rio de Janeiro: Bertrand Brasil, 2013, p. 83.

36 MORIN, Edgar. A Via para o futuro da humanidade, p. 83. 
Portanto, nesse modelo - da Democracia Participativa -, a Participação é uma condição indispensável dada a sua essencialidade na tomada das decisões, como forma de projetar os sujeitos de direito para os ideais de verdadeira Liberdade, ou seja, de Liberdade praticada no Estado, funcionando como um sistema efetivo e praticável de freio às decisões que operem nocividade velada ou aberta à sociedade ${ }^{37}$.

A Democracia tem como um de seus objetivos fundamentais o de fomentar a máxima utilização das capacidades individuais no interesse da comunidade. $\mathrm{O}$ homem que não participa dos assuntos políticos vê diminuídas suas capacidades intelectuais e morais e limitados e frustrados seus sentimentos. A participação pressupõe um valor democrático em si mesmo considerado, na medida que constitui uma expressão da autonomia e, em definitivo, da liberdade do ser humano. ${ }^{38}$.

Nesse contexto, não há como se negar a ideia de um mundo globalizado e em expansão na produção de bens e serviços. Perguntar de que modo se verá o Planeta a partir dessa expansão interna e considerar a ideia participativa é o grande dilema.

Quanto mais forte e bem dirigido for o Poder Público, muito mais eficácia de atuação será observada, mesmo que sozinho não seja capaz de possuir controle sobre os processos transnacionalizantes.

\section{CONCLUSÃO}

A Democracia exige que OS processos econômicos ${ }^{39}$ venham a ser inseridos em processos sociais, com regras nacionais ou transnacionais, o que evidencia a necessidade de que

37 Exemplos legislativos são inúmeros e a casuística na produção legislativa é uma constante.

38 CRUZ, Paulo Márcio. A democracia representativa e a democracia participativa.

Direitos Fundamentais \& Justiça. Porto Alegre, n 13, 2010, p. 214.

39 Como fundamento da idéia de Desenvolvimento. 
tais regras sejam postas de modo que se possa identificar os ideais de cada um dos povos, pois considerar que um conceito geral de ordenamento transnacional pudesse dar conta do que se chama globalização é não considerar o sujeito como sujeito nacional de direito.

O conflito entre a ideia de Democracia, ideal ou não, revela a categoria cunhada por Mouffe ${ }^{40}$ como Democracia Radical, a qual exige que se reconheça a diferença, o particular, o múltiplo, o heterogêneo. $\mathrm{O}$ universalismo não sofreria qualquer modo de repulsa, senão seria considerado de modo particular ao mesmo tempo em que seria pensado em conjunto ${ }^{41}$, sem ser, no entanto, paradoxal, o que parece viabilizar o enredo de Constitucionalismo Intercultural com Democracia Participativa.

\begin{abstract}
In the midst of the complex world, where governments now appear with supranational aspects, when corporations alike supplant territorial physical spaces, questions emerge that propel researches, since the composition of this whole social amalgam is made of people, unseen invisible subjects from which the repercussions of decision-making affect directly. Therefore, what this study focus to explore is the need that this same subject has to have the means to participate in such decisions without being for the sake of suffrage. That their participation is effective, dignified and from which the consequences are directed and redirected according to their real needs, in a dynamic and effective way.
\end{abstract}

Keywords: Subject. Intercultural constitutionalism. Participative democracy.

40 MOUFFE, Canthal. O Regresso do Político, p. 27.

41 Para Ulrich Beck em sua obra Que és la globalización: falácias del globalismo, respuestas a la globalización, p. 93, seria a idéia do "pensar globalmente e agir localmente". 


\section{REFERÊNCIAS}

BECK, Ulrich. La democracia y sus enemigos. Tradução de Daniel Romero Álvarez. Barcelona. Ediciónes Paidós Ibérica. 2000.

BECK, Ulrich. Que és la globalización: falácias del globalismo, respuestas a la globalización. Tradução de Bernardo Moreno e Maria Rosa Borrás. Barcelona. Paidós. 1998.

CRUZ, Paulo Márcio. Democracia e Pós-Modernidade. Itajaí: Univali. 2006.

CRUZ, Paulo Márcio. A Democracia Representativa e a Democracia Participativa. Universidade de Alicante. Espanha. 2007.

CRUZ, Paulo Márcio. A democracia representativa e a democracia participativa. Direitos Fundamentais \& Justiça. Porto Alegre, no 13, p. 202-224, 2010.

FARIA, José Eduardo. Direito e Globalização Econômica. São Paulo: Malheiros.1996.

FERRAJOLI, Luigi. Poderes salvajes. La crisis de la democracia constitucional. Madrid: Editorial Trotta, 2011.

FERRER, Gabriel. Seminário - Engenharia Social e Sustentabilidade. UNIVALI. Novembro de 2012.

GOULART, Clóvis de Souto. Formas e Sistemas de Governo. Porto Alegre: Fabris Editor.1995.

HELLER, Hermann. Escritos Políticos. Madrid: Alianza Universidad, 1985.

LASALLE, F. Que és una Constitución. Tradução de W. Roces. Siglo Viente. Buenos Aires. 1964.

LIPOVETSKY, Giles. A era do vazio: ensaios sobre o individualismo contemporâneo. Tradução Therezinha Monteiro Deutsch - Barueri, SP: Manole, 2005.

MELO. Osvaldo Ferreira de. Dicionário de Política Jurídica. Florianópolis: OAB-SC Editora. 2000.

MOUFFE, Canthal. O Regresso do Político. Tradução de Ana Cecília Simões. Lisboa: Gradiva. 1996. 
RUIZ, José Juste. La Proteción del Médio Ambiente en el Âmbito Internacional. MADAS. Alicante. Espanha. 2007.

SANTOS, Boaventura de Souza. Pela mão de Alice: o social e o político na pós-modernidade. São Paulo: Cortez. 1995.

SANTOS, Boaventura de Souza. Organizador. Democratizar a

Democracia: os caminhos da democracia participativa, 2a Ed. Rio de Janeiro: Civilização Brasileira, 2003.

WOLKMER, Antonio Carlos. Ideologia, Estado e Direito. 4 ed.São Paulo: Revista dos Tribunais. 2003.

W. SACHS (editor). Diccionario del desarrollo. Una guía del conocimiento como poder. Peru: PRATEC. 1996. 
